\title{
Novazelandiella gen. n. (Acari, Oribatei, Hammeriellidae), a new genus of mites from New Zealand.
}

\author{
Adilson D. Paschoal ${ }^{1}$
}

\begin{abstract}
A new genus Novazelandiella (Acari, Oribatei, Hammeriellidae) is described. The type species, Pedrocortesella nigroclava Hammer, 1966, New Zealand, is redescribed from the holotype (Zoologisk Museum, Denmark) and from six specimens (Acarology Laboratory, USA) identified as being co-specific with the type material, after being confronted with it. Up to the present time, the new genus is monotypic and restricted to New Zealand, being close to the South American genus Hammeriella Paschoal.
\end{abstract}

\section{Novazelandiella gen. $\mathbf{n}$.}

Type species: Pedrocortesella nigroclava Hammer, 1966.

Diagnosis - Novazelandiella is close to Hammeriella Paschoal, 1989, from which it differs mainly by the following characteristics: Genitoanal and epimeral regions with cuticular - thickenings and wrinklings; apo ro a strong bar; apo ro, apo ex with no mammillate protuberances; le lateral; ex on apo ex; bothridium dorsal, well apart from notogaster; ss globular, black, totally enclosed in bothridium; hl, psl lanceolate; ps2, ps3 away from ps1, anterior to r2; r2 dorso-lateral, well at notogastral margin; lyrifissures small, ip inclusively; genital and anal apertures not blended; anal aperture pyriform; genitalia proximal margin at the level of coxae III; gl $-\mathrm{g} 2, \mathrm{~g} 2-\mathrm{g} 3$ closer together than the other setae; adl distal; Tb I apophysis long; (it),(tc) long, not on apophyses; d Tb I anterior to 1'; fi Tb II very close to d; v' Ge II - IV absent; pl' Ts IV present; leg segments long.

Description - Body of clarified specimens covered by cerotegument forming small microtubercles; legs covered by a thick polygonal mass. Notogastral, prodorsal and ventral region cuticle foveate; genitoanal region with cuticular thickenings; epimeral region cuticle wrinkled. Exuviae held by adults. Apo le absent; apo ro with a strong transversal bar; apo ro, apo ex without mammillate protuberances; all other apodemata well sclerotized. Prodorsum with no transversal furrow at tooth $\mathbf{p}$ area. le lateral, on small apophysis, anterior and away from - ro; ro lateral; ex short, on apo ex; in short, lanceolate; bothridium dorsal, away from notogastral margin; ss globular, 
black, very short, totally enclosed in bothridium. ps 1 further apart from its homologous seta than $h \mathbf{l}$, being short, lanceolate; integument invaginated between ps1, ps2, ps3 close together, away and at a higher level than ps1, both anterior to $\mathbf{r} 2$; hl terminal, very close to its homologous seta, being short, lanceolate; r2 (1p) dorsolateral, well at notogastral margin, close to ip; r3 (1m) absent. Small lyrifissures, ip inclusively. Notogaster flat, rounded. Large size mites, from 700 to $900 \mu$. Epimeral spodemata with strong, undulated apodematic bonds; apo IV as a "hat" over genitalia; epimeral chaetotaxy 3 : 1:3:3. Genital and anal apertures close together but not blended; anal apertures pyriform; genitalia proximal margim at the level of coxae III; genital and anal plates foveate; apo ag, apo ad present; genitoanal chaetotaxy $7 \cdot 1-3-3$; genital setae on a sole longitudinal row; $\mathbf{g} 1-\mathbf{g} 2, \mathbf{g} 2-\mathbf{g} 3$ further apart than the other setae; anal setae also on a sole longitudinal - row; ag postero-lateral, at a short distance from genitalia; ad1 posterior to anal plate. Tb I apophysis long, covering proximal end of tarsus; tarsi pedicels extremely short, with three equally strong claws; Ts I famulus enclosed; leg segments very long; tarsi (it), (tc) not on apophyses, being long, slender, covered with long spines all over the surface; (u), (a), s well developed with long spines ventrally; d Tb I anterior to 1'; fi Tb II very close to d; $\mathbf{v}^{\prime} \mathrm{Ge}$ II, III absent; $\mathrm{ft}^{\prime}$ Ts III close to ft". pl' Ts IV present; all other chaetotaxic features as for the family (PASCHOAL, 1988). Leg chaetotaxy: Ts.19(2)-17(2)-16-15; Tb.4(2)-5(1)-4(1)-4(1); Ge.4(1)-3(1)-2(1)-2; Fe.5-5-3-2; Tr.1-1-2-1.

Discussion - The generic name refers to the region of occurrence of the species, i.e., New Zealand. For a complete literature survey see PASCHOAL, 1987.

Novazelandiella nigroclava (Hammer, 1966) comb. $\mathbf{n}$.

Pedrocortesella nigroclava Hammer, 1966: 50, fig. 63.

Types - Female holotype no. 87, collected by Marie Hammer from mosses and lichens on a tree, Keri-Keri, New Zealand, with no collecting date, preserved in alcohol, most tarsi and tibiae missing. Depository: Zoologisk Museum, Copenhagen, Denmark. Three males, three females no. 24-XI-1961 collected by J.H. Styles on November 24, 1961, from New Zealand (locality not mentioned). Depository: Acarology Laboratory, the Ohio State University, Columbus, USA, and Departamento de Zoologia, E. S. A. "Luiz de Queiroz", Piracicaba, SP, Brasil.

Diagnosis - N. nigroclava is close to Hammeriella australis (Hammer, 1962), from which it differs mainly by the following characteristics; body and legs microtubercles small, rare; notogastral foveae very close one to the other; prodorsum with no reticulum; exuviae with ps1 spatulate; apo ro strong; ex on apo ex; different arrangement of apo in, apo bo; le lateral; bothridium dorsal, well apart from notogastral margin; ss very short, globular, totally enclosed 
in bothridium; small lyrifissures; glandular opening lateral to im; hl not too close to its homologous seta; ps2, ps3 anterior to r2; smaller species; genital and anal apertures not blende; anal aperture pyriform; genitalia proximal margin at the level of coxae III; g1 - g2, g 2 - g3 further apart than the other setae; spiny genital setae; adl posterior to the anal plate; with a mammillate salience close to pedotectal tooth p; claws almost equaly developed; leg segments quite long; (it), (tc) not on apophyses; tibial apophysis long; p1" posterior to pv" on Ts II;

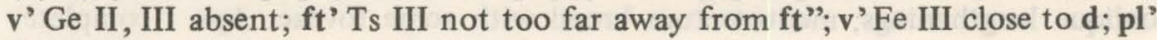
Ts IV present.

Description - Integument - Cuticle of clarified specimens granulate, covered by a thin layer of cerotegument with no large microtubercles; notogastral, prodorsal and ventral microtubercles indistinguishable, forming a compact mass of very small granules; leg cerotegument abundant, high, forming - polygonal reticulum. Notogastral foveae very close one to the other foming an hexagonal reticulum on central portion; laterally the reticulum is irregular or inexistent. Prodorsum without reticulum but with areas of heavy sclerotization delimiting semicircular foveae, abundant medianly and anterolaterally. Foveae also on lateral metapodosome and on genitoanal region, as large and regularly distributed circles; genital and anal plates foveate, with semicircular small foveae. Epimeral cuticle wrinkled, with well sclerotized elongated saliences. Exuviae held by adults; last instar exuvia with two distal, straight, spatulate, strong setae, set on tubercles coalescent at the bases, and two small other setae set in small tubercles away from the other. Prodorsum - Apo le absent; apo ro strong, slightly behind ro, originated on acetabulum I, forming a well sclerotized arc across prodorsum, presenting a loop forming ex tension pointed to bothridium; apo $\mathrm{c}$ as two well sclerotized foveate plates; apo ex a well sclerotized longitudinal bar originated on acetabulum II, being posterior to bothridium, bearing ex at distal end; a J-shaped bar occurs at apo ex base; apo in a U-shaped bar weakly fused with apo ro loop; apo bo a short V-shaped bar, the apex turned laterally to the out-side. Prodorsum with no transversal furrow at pedotectal tooth $\mathbf{p}$ area. le anterior to ro, away from it, set on small apophysis close to the apical border, being smooth, slender, bent to the sagital plane the tip not corssing the homologous seta; ro lateral, smooth, bent to the sagital plane; ex slender, short, on apo ex, behind and below bothridium; in short, laceolate, upturned, on strong tubercle; bothridium dorsal, oblique, globet shaped, the opening turned frontward, set well - apart from notogaster margin; distance between bothridia $123 \mu(\mathrm{M}), 151 \mu(\mathrm{F})$; ss globular, black, covered by cerotegument, very short, totally enclosed in bothridium; ss length $42.8 \mu(\mathrm{M}), 39.3 \mu(\mathrm{F})$. Prodorsum length $220 \mu(\mathrm{M}), 233.7 \mu(\mathrm{F})$; width $347.7 \mu(\mathrm{M}), 357.5 \mu(\mathrm{F})$. Notogaster Dorsum flat, rounded. Notogastral tectum present between lines bng, lambda. Five pairs of small lyrifissures; ia at the antero-lateral border, almost parallel to notogastral margin; im, ip smaller than ia, oblique to the margin; ip at notogastral postero-lateral border, not as close to each other as drawn by Hammer; ih, ips as large as im. Latero-abdominal gland short, narrow, opened laterally to im. Five pairs of notogastral setae; r2(1p) dorso-lateral, well at notogastral margin, close to ip, being short, straight, lanceolate, covered with cerotegument; hl distal very close to its homologous seta, being short, straight, lanceolate, 
covered - with cerotegument; psl similar to the previous setae, below hl; integument between ps1 deeply invaginated, well sclerotized; ps2, ps 3 close together away from ps1, both anterior to $\mathrm{r} 2$. Notogaster length $508 \mu(\mathrm{M})$, $577.5 \mu(\mathrm{F})$; width $488.1 \mu(\mathrm{M}), 550 \mu(\mathrm{F})$; length/width $1.04(\mathrm{M}), 1.05(\mathrm{~F})$. Epimeral region - a, $\mathrm{m}$ long, smooth, slender; $\mathrm{m}$ longer than a, set laterally, bent to the sagital plane; a proclinate; labio-genal apodeme narrow, well sclerotized; $\mathbf{h}$ short, proclinate, on a transversal apodeme presenting reclinated oblique lengthenings; mentotectum broad with some foveae. Apo I complete, well developed at coxal region, close to acetabulum I, presenting a transversal bar linking the homologous parts; apo II incomplete, strong at coxal region, also with a transversal bar delimiting epimeral furrow II on epimeral region; apo sj incomplete, well sclerotized at coxal region, with a transversal bar on epimeral region, linking the homologous parts; sj furrow delimited; apo Ilil long, incomplete, with no transversal bar; epimere III furrow well delimited; apo IV short, incomplete, with a transversal bar resembling a "hat" over genitalia, delimiting epimeres III, IV. Epimeral chaetotaxy $3: 1: 3: 3$; epimeral setae equally long. Genitoanal region - Genital and anal apertures close together but not fused, the contours still visible at the contact area; genital aperture square; anal aperture pyriform; genitalia anterior margin at the level of coxae III. Genitalia length $132.1 \mu(\mathrm{M}), 165 \mu(\mathrm{F})$; width $114.4 \mu(\mathrm{M}), 137.5 \mu(\mathrm{F})$; anal plate length $178.5 \mu(\mathrm{M}), 220 \mu(\mathrm{F})$; width $124.9 \mu(\mathrm{M}), 158 \mu(\mathrm{F})$. Genital and anal plates inner margins weakly sclerotized, outer margins sclerotized; apo,ag, apo ad present, as broad bars of undulated contours. Genitoanal chaetotaxy 7 - 1 . 3 - 3; genital setae short, slender, spiny, on a sole longitudinal row, the last four pairs almost equidistant; g1 - g2, g2 - g3 further apart than the other pairs; anal setae also on a sole longitudinal row, being short, thick, spiny; ag on apo ag, lateral to genitalia, at a short distance from it; ad not on tubercle; ad 3 at a height equivalent to half the plate, away from it; ad 2 on apo ad, close to the plate; adl posterior to the anal plate. Lateral features - Tectopedia absent; with a pedotectal tooth p very similar to a true pedotectum when seen from above, being not auriculiform however; lateral carenae present; sejugal apophysis absent; acetabula I, II integument and cotyloid forming a blunt structure; with a mammillate salience posteriorly to p. Legs - Ts - Tb, Tb - Ge, $\mathrm{Ge}-\mathrm{Fe}$ articulations on proximal sockets, i. e., sockets on proximal ends of tarsi, tibiae, genua; femoral and trochanteral trachaeae present, stigma large, opened at the base of the segments. Ts I, II with distal apophyses; enclosed famulus on Ts I; $\mathrm{Tr}$ and $\mathrm{Tr}-\mathrm{Fe}$ articulations of all legs outside acetabula; femora orientation after articulation with trochantera almost straight; tarsi pedicels extremely short; three equally strong claws; leg segments very long. Proral setae well developed ex except on Ts I; (it), (tc), long, slender, not on apophyses, covered with long spines all over their surfaces; (u), (a), s smaller, with long spines ventrally only; all other setae with short spines, not set on apophyses. Ts. I - ft" dorsal, very close to omega; ft' dorso-lateral, not too close to ft"; pv" anterior to pv', away from it; pl', pl" at the same level, on proximal end of segment;

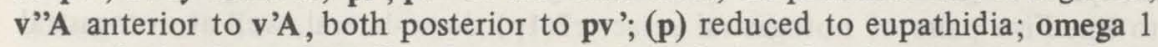
paraxial, slender and smaller than omega 2 , both on a dorsal antiaxial apophysis of tarsus; omega 2 antiaxial; famulus enclosed; Ts length $137.5 \mu(\mathrm{M}), 151.2 \mu(\mathrm{F})$. 
Tb. I - d anterior to 1 '; ', $\mathbf{v}$ 'at the same transversal plane; tibial apophysis long, covering proximal half of tarsus, being dorsal, antiaxial; fil long, antiaxial; fi2 short, antiaxial, a little behind fil; Tb length - $268 \mu(\mathrm{M}), 275 \mu(\mathrm{F})$. Ge. I - 1', 1 ", $v^{\prime}$ on proximal half, almost at the same transversal level; $d$ dorsal, anterior and very close to sigma; sigma slender, setiform; Ge length $82.5 \mu$ (M, F). Fe. I - d long; 1', 1" on distal end, almost at the same transversal plane; two v" posterior to d; Fe length $275.7 \mu(\mathrm{M}), 288.5 \mu(\mathrm{F}) ; \mathrm{Tr}$. I - one sole seta; $\operatorname{Tr}$ length $55 \mu(\mathrm{M}, \mathrm{F})$. Ts. II - ft" anterior to $\mathrm{ft}^{\prime}$ ', not too far from it; pl' present, at the same pl" transversal plane; pl" posterior to pv"; pv' anterior to pv"; omega 1 close to omega 2, paraxial, a little large - than omega 2; Ts length $165 \mu(\mathrm{M}, \mathrm{F})$; Tb. II - d dorsal, at distal margin of the segment, quite close to fi; 1 ', 1 "almost at the same transversal plane, at half of the segment; (v) anterior to (1); fi antiaxial, long, on small salience at distal tibia; Tb length $165 \mu(\mathrm{M})$, $178.7 \mu(\mathrm{F}) ; \mathbf{G e}$ II - d long, at distal end of the segment; 1', 1' at the same level; v'absent; sigma setiform, short, antiaxial, close to d; Ge length $68.7 \mu(\mathrm{M}, \mathrm{F})$; Fe II - d long; 1', 1" distal; two v", one proximal, one distal; $\mathrm{Fe}$. length $233.7 \mu(\mathrm{M}, \mathrm{F})$; $\mathbf{T r}$. II - one sole seta, ventral; $\operatorname{Tr}$ length $55 \mu(\mathrm{M}, \mathrm{F})$; $\mathrm{Tr}$. III - ft' present, posterior, not too far from ft"; $\mathbf{p l}$ "'absent; pv'posterior to ft', anterior to $\mathbf{p v " ;}$ " pl' posterior to pv'; solenidia absent; Ts length $151.2 \mu(\mathrm{M}), 156 \mu(\mathrm{F})$; Tb. III - $\mathbf{d}$ antiaxial, at distal end; 1' posterior to (v), at half of the segment; $\mathbf{v}$ ', v" almost at the same transversal plane; fi antiaxial, close to d; Tb length $206.2 \mu$ (M, F); Ge III - d antiaxial, close to solenidium; l' at half of the segment; v' absent; Ge length $68.7 \mu$ (M, F); Fe. III - d well developed; 1', v' close to d; Fe. length $192.5 \mu(\mathrm{M}, \mathrm{F})$; Tr. III - 1', 'v' present; Tr length $89.4 \mu(\mathrm{M}), 96.4 \mu(\mathrm{F})$. Ts. IV - ft' absent; (it) present; l" absent; pv' anterior to pv'"; pl' at the level of pv"; solenidia absent; Ts length $151.2 \mu(\mathrm{M}), 165 \mu(\mathrm{F})$. Tb. IV - as in Tb III; Tb length $247.5 \mu(\mathrm{M}), 261 \mu(\mathrm{F})$. Ge IV - d, 1 ' as in Ge III; solenidium - absent; Ge length $68.7 \mu(\mathrm{M}, \mathrm{F}) . \mathbf{F e}$. IV - d long; v' proximal; Fe length $192.5 \mu(\mathrm{M}, \mathrm{F})$. Tr. IV - one $\mathbf{v}$ seta; Tr length $165 \mu(\mathrm{M}), 178.7 \mu(\mathrm{F})$. Leg chaetotaxy Ts. 19(2) $17(2)$ - 16-15; Tb. 4(2) - 5(1) - 4(1) - 4(1); Ge. 4(1) - 3(1) - 2(1) - 2; Fe. 5 - 5 $3-2 ; \operatorname{Tr} .1-1-2-1$.

Geographical distribution and habitat - Keri Keri, New Zealand, in mosses and lichens on a tree.

Discussion $-N$. nigroclava was described on the basis of a mutilated specimen with most tarsi and tibiae missing. In placing it in Pedrocortesella, Hammer (1966) demonstrates her uncertainty by setting a question mark before the generic name. In 1974, six specimes collected in New Zealand by J. H. Styles, beloging to the Acarology Laboratory, the Ohio State University, U.S.A., were studied by PASCHOAL (1975), PASCHOAL \& JOHNSTON (1982), being provisionally identified as Pedrocortesella nigroclava. In 1979. In 1979, the holotype of P. nigroclava, and the Styles' specimens were loaned by the Zoologisk Museum, Copenhagen, and by the Acarology Laboratory, U.S. A., respectively. After the comparative study it became evident that the specimens collected by Styles were in fact co-specific with the one described by Hammer. This finding allowed a detailed description of the species, presented in this 
publication, and the erection of the new genus Novazelandiella, after being confronted with $P$. pulchra, the type species for Pedrocortesella.

\section{Key to genera of Hammeriellidae.}

1. le lateral, bothridium away from notogaster; ss totally enclosed in bothridium; ps2, ps3 anterior to r2; ip small; tibial apophysis long; leg segments very long . ............ Novazelandiella Paschoal

le dorsal to dorso-lateral; bothridium close to notogaster; ss projecting outside bothridium; ps2, ps 3 posterior to $\mathbf{2}$; ip long; tibial apophysis short; leg segments not too long $\ldots \ldots \ldots \ldots \ldots \ldots \ldots$

2. Adults with exuviae; le dorsal; ss globular; $\mathbf{r} 2$ dorsal; notogaster rounded; without femoral crests; (it), (tc) on strong apophyses; p1' Ts IV absent . . . . . . . . . . . . . . . Hammeriella Paschoal

Adults without exuviae; le dorso-lateral; ss slightly clavate; r2 lateral; notogaster ovate; with femoral crests; (it), (tc) not on apophyses; p1' Ts IV present . . . . . . . . . . Andesperuviella Paschoal.

\section{REFERENCES}

HAMMER, M. 1966. Investigations on the oribatid fauna of New Zealand. Part 1. Biol. Skr. Dan. Vid. Selsk. 15(2):5-108.

PASCHOAL, A. D. 1975. A revision of the Gymnodamaeidae (Acari, Oribatei): A numerical taxonomic study. Ph. D. Dissertation, the Ohio State University, 374 pp.

PASCHOAL, A. D. 1987. A revision of the Plateremaeidae (Acari, Oribatei) Revta bras. Zool. 3(6):327-356.

PASCHOAL, A. D. 1989. Description of a new genus - Hammeriella gen. n. - from South America and a new family - Hammeriellidae fam. n. (Acari, Oribatei). Revta bras. Zool., 6(1):17- 24 .

PASCHOAL, A. D. \& D. E. Johnston. 1982. A numerical taxonomic revision of the Gymnodamaeidae (Acari, Oribatei). Revta bras. Biol. 42 (2): 439-459. 